\title{
HLA-DP4 Positive Cells Present
}

National Cancer Institute

\section{Source}

National Cancer Institute. HLA-DP4 Positive Cells Present. NCI Thesaurus. Code C142096.

An indication that the expression of major histocompatibility complex, class II DP protein in which haplotype of the alpha subunit is HLA-DPA1*0103 and haplotype of the beta subunit is either HLA-DPB1*0401 or HLA-DPB1*0402 allele of the HLA-DPB1 gene is present in a cell or tissue sample. 